\title{
O sistema hidráulico superior na arquitetura sacra gótica. Casos de estudo em Lisboa.
}

\author{
The superior hydraulic system in gothic sacra architecture. Cases of study in Lisbon.
}

Ana Patrícia Alho ${ }^{1}$; 1E-mail: ana_alho@hotmail.com Faculdade de Letras da Universidade de Lisboa
Resumo: O presente texto vem na sequência da tese de doutoramento que nos defendemos na Faculdade de Letras da Universidade de Lisboa, sob o tema: "O sistema hidráulico na arquitetura sacra gótica em Portugal dos séculos XIII a XVI". Este projeto parte de um conceito de arquitetura entendida como um conjunto estruturado de sistemas que, faseadamente, constituem preocupação do mestre construtor. Neste conjunto de sistemas está incluído o sistema hidráulico que dividimos em subsistema hidráulico superior e subsistema hidráulico inferior, sendo que neste caso específico só nos iremos referir ao primeiro subsistema evocado. No que diz respeito ao subsistema hidráulico superior dividimos o mesmo por soluções encontradas em diversos edifícios pertencentes à arquitetura gótica e tardogótica portuguesa e estrangeira, para com isto podermos concluir quais as soluções mais adotadas e os elementos aqui tectónicos mais usados como auxiliares do sistema hidráulico superior.

Neste artigo propomo-nos a focar a nossa atenção para o sistema hidráulico superior presente em Lisboa: Mosteiro de Santa Maria de Belém, Ermida de S. Jerónimo, Igreja da Conceição a Velha e Catedral de Lisboa.

Palavras Chave: Hidráulica, Arquitetura, Gótico, Gárgulas

Kev Words: Hydraulic, Architecture, Gothic, Gargovles 


\section{ponteditora}

\section{Introdução}

O sistema hidráulico é um subsistema arquitectónico, que pode ser compreendido atendendo ao seu duplo desenvolvimento: um primeiro que se refere à água potável, ao nível do solo (subsistema hidráulico inferior), e um segundo que compreende as águas pluviais (subsistema hidráulico superior). No entanto, nestes dois subsistemas deparamo-nos com três aspectos comuns com elevada importância para a funcionalidade de qualquer edifício: captação, distribuição e evacuação. Existe também uma articulação entre estes dois subsistemas, condicionando a organização arquitectónica.

O sistema hidráulico é sem dúvida fundamental para o bom funcionamento dos edifícios, visto tratar-se de um vasto conjunto de elementos que constituem um sub -sistema da organização arquitectónica geral: coberturas, caleiras de escoamento, gárgulas e goteiras, roços em contrafortes e arcobotantes, canalizações no solo, entre outros ${ }^{1}$. Todo o sistema hidráulico demonstra uma elevada complexidade e cuidado, desde sempre que uma das primordiais preocupações do mestre/arquitecto ao conceber o edifício, foi conduzir as águas pluviais para o exterior da zona coberta, sendo também uma das grandes preocupações demonstradas aquando dos restauros efectuados nos edifícios ao longo dos anos.

Após a análise inicial ao sistema hidráulico superior europeu (França, Espanha, Itália, Inglaterra e Alemanha), encontrámos várias soluções hidráulicas para cada um dos edifícios, criando posteriormente as tipologias, compostas por dez grupos: I. Telhados de duas ou mais águas com gárgulas ou goteiras; II. Terraços inclinados com gárgulas ou goteiras; III. Gárgulas duplas no arcobotante; IV. Gárgulas duplas no contraforte; V. Canalização interior no contraforte; VI. Utilização do contraforte como auxiliar do sistema hidráulico; VII. Utilização do arcobotante como auxiliar do sistema hidráulico; VIII. Utilização do varandim como auxiliar do sistema hidráulico; IX. Utilização de taças em ferro; X. Utilização de arcobotantes duplos.

Quanto ao sistema hidráulico superior nacional, encontramos várias soluções criando posteriormente as respectivas tipologias: I. Telhados de duas ou mais águas, sem gárgulas ou goteiras; II. Telhados de duas ou mais águas, com gárgulas ou goteiras; III. Um telhado de duas águas, sem gárgulas ou goteiras; IV. Utilização do arcobotante com taças; V. Utilização do arcobotante sem taças; VI. Telhados com duas ou mais águas, terraços, gárgulas ou goteiras; VII. Claustros. 
1. Catedral de Lisboa: descrição histórica, artística, conservação e restauro e subsistema hidráulico superior

O primeiro impulso edificador da catedral de Lisboa deu-se no ano de 1147, nos séculos seguintes efetuaram-se as transformações mais marcantes para a construção da catedral: a capela de Bartolomeu Joanes, a nova cabeceira com deambulatório (mandada construir por D. Afonso IV entre os anos de 1325 e 1357), para panteão familiar) e o claustro Dionísio, "Noticiou-se que esta obra se fazia por 1332, sendo o seu mestre João Anes. Certamente terá

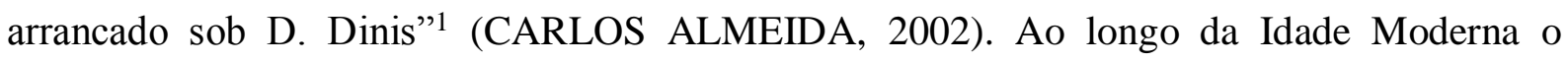
edifício foi objeto de vários restauros e enriquecimentos arquitectónicos e artísticos, entre eles, a sacristia de meados do século XVII, que sofreu duas campanhas de restauros durante a primeira metade do século XX, sendo o seu principal objectivo a "restituição" da atmosfera medieval a todo o conjunto monástico. O claustro gótico é composto por duplos arcos com capitéis esculpidos. Aquando da visita de Thomas Pitt a Portugal, o autor dá-nos conta do estado em que o edifício se encontrava, tal como podemos constatar a partir da sua pena: "A Sé Velha, ou Catedral, não está assim tão destruída que não possa ser facilmente reparada, tal como é intenção do Rei. É de grande antiguidade, embora não esteja convencido de que seja mourisca, tal como se pretende. A fachada ocidental é ladeada por duas torres que têm cúpulas para sinos, uma delas caiu."3 (MARIA JOÂO NETO, 2006). No pátio do claustro, podemos ver os vestígios da atividade arqueológica desenvolvida ao longo dos anos, que pôs a descoberto entre outras coisas, uma cisterna. As coberturas em telhado de duas águas estão presentes na nave central, nos terraços das naves laterais, na capela de Bartolomeu Joanes e nas capelas do deambulatório. Existem também coberturas de duas e quatro águas no claustro, no camarim do Patriarca e na sacristia. Na capela-mor deparamo-nos com coberturas de sete águas.

Apesar das várias fases de construção ao longo dos séculos e dos restauros efectuados no edifício, encontrámos algumas soluções de descarga das águas pluviais, que dividimos em três grupos: uma primeira que se refere às gárgulas que estão colocadas nas duas torres da fachada em que existem um conjunto de duas gárgulas em cada uma delas. Estas estão viradas para o interior do edifício, descarregando sobre o telhado da nave central. Quanto as estas torres devemos ter em conta o facto de terem sido modificadas por D. Jorge Costa, no século XV sofrendo também uma campanha de restauro no inicio do século XX levada a cabo pela 
Direcção Geral dos Edifícios e Monumentos Nacionais, o que nos leva a concluir que também as gárgulas aí existentes são objeto de restauro, tratando-se de uma solução pouco prática e sensata ao nível hidráulico, pois faria muito mais sentido existir uma descarga de águas para o exterior do edifício e não para o interior, acabando por dificultar o escoamento das águas pluviais. Estas águas são descarregadas para o "interior" da nave central sendo enviadas para um telhado que está entre as duas torres e daí são direcionadas para um canal, seguindo a água pelos orifícios que foram feitos por cima do portal principal.

A segunda solução diz respeito às gárgulas que se encontram viradas para o exterior do edifício, onde encontrámos dois tipos diferentes: um que descarrega as águas directamente para a rua e outro em que as gárgulas estão colocadas em cima dos contrafortes escalonados, o que leva a que as águas escorreguem primeiro pelos contrafortes e só depois são enviadas para a rua. A última solução, encontra-se no interior do claustro onde existem poucas gárgulas sendo que nenhuma é referente à época da fundação do claustro e algumas goteiras no entanto todas têm a função de conduzir as águas do terraço para o interior do claustro. Composto por dois terraços na cabeceira da igreja a que dão nome de "Claustro Alto" a água cai no primeiro terraço que é inclinado a uma água, vai para o canal que o circunda seguindo pelos orifícios e daí parte para o segundo terraço, também inclinado a uma água, com um canal que o circunda para as gárgulas e finalmente para o exterior.

É importante notar que existe um conjunto de arcobotantes que foram restaurados pela Direcção Geral dos Edifícios e Monumentos Nacionais no início do século XX composto por canais rasgados para que as águas circulem ordenadamente tal como encontramos noutros edifícios, no entanto neste caso não tem qualquer sentido uma vez que os arcobotantes estão "suspensos" e tapados no início do canal com cimento de massa.

Após a investigação levada a cabo por Lúcia $\operatorname{Rosas}^{1}$ (LUCIA ROSAS, 1995) podemos concluir que existiram várias campanhas de restauro efectuadas na catedral de Lisboa durante os séculos XIX e XX: 


\begin{tabular}{|c|c|c|c|c|}
\hline $\begin{array}{l}\text { Campanhas } \\
\text { de Restauro }\end{array}$ & Datas & Encomendadores & Autores & Intervenções \\
\hline I & $1856-1864$ & M. O.P. & & \\
\hline II & 1898 & & $\begin{array}{l}\text { Augusto } \\
\text { Fuschine }\end{array}$ & $\begin{array}{l}\text { Demolição no interior e } \\
\text { remoção de entulhos }\end{array}$ \\
\hline III & 1899 & M. O. P. & & \\
\hline IV & 1904 & & & $\begin{array}{l}\text {.Estavam restauradas as } \\
\text { janelas geminadas, } \\
\text { lateral e frontal da Torre } \\
\text { Norte } \\
\text {. Concluído o restauro } \\
\text { da porta lateral norte }\end{array}$ \\
\hline $\mathrm{V}$ & 1906 & & & $\begin{array}{l}\text { Restauro da Capela de } \\
\text { Bartolomeu Joanes } \\
\text {. A torre norte estava } \\
\text { concluída e rematada } \\
\text { com uma agulha em } \\
\text { cimento } \\
\text {. Início do coroamento } \\
\text { da torre sul } \\
\text {. Restauro do } \\
\text { deambulatório } \\
\text {. Abertura de uma janela } \\
\text { na testeira da ala } \\
\text { oriental do claustro, } \\
\text { voltada a sul }\end{array}$ \\
\hline VI & $1908-1911$ & & $\begin{array}{l}\text { António } \\
\text { Couto } \\
\text { Abreu }\end{array}$ & $\begin{array}{l}\text { Restauradas as janelas } \\
\text { geminadas da torre sul } \\
\text {. Colocação de uma }\end{array}$ \\
\hline
\end{tabular}




\begin{tabular}{|c|c|c|}
\hline & & $\begin{array}{l}\text { janela "typo românico" } \\
\text { sobre a porta lateral } \\
\text { norte } \\
\text {. Restauro de uma sala } \\
\text { ogival por cima do } \\
\text { "Camarim do Patriarca" } \\
\text {. Restauro da Capela de } \\
\text { São sebastião na fachada } \\
\text { sul } \\
\text {. Abertura de janelas } \\
\text { superiores na Charola, } \\
\text { nas capelas de S. } \\
\text { Sebastião e de Nossa } \\
\text { Senhora da Piedade }\end{array}$ \\
\hline VII & 1916 & $\begin{array}{l}\text { Obras nas capelas do } \\
\text { deambulatório e claustro }\end{array}$ \\
\hline VIII & 1923 & Obras no portal \\
\hline
\end{tabular}

Gráfico n. ${ }^{\circ} 1$ - Campanhas de restauro efectuadas na catedral de Lisboa durante os séculos XIX e XX 
2. Mosteiro de Santa Maria de Belém: descrição histórica, artística, conservação e restauro e subsistema hidráulico superior

A primeira pedra do mosteiro foi lançada em Dia de Reis, em 1501 ou 1502. Entre 1513 e 1514 o rei D. Manuel I adquiriu cerca de 22 terrenos localizados onde está hoje implantado parte do mosteiro. Não sabemos, quem foi o autor do projecto do complexo monástico, no entanto de certeza que se trata de um projecto diferente daquilo que foi planeado e do que foi efetivamente edificado, conforme o testemunho de Frei Diogo de Jesus: "chegou a obra só à quarta parte do que o typo, rascunho e original mostrava: de 4 claustros só um acabado, de 4 dormitórios um e ficou imperfeito"5 (JOSE ALVES, 1991). A coordenação do estaleiro por parte de Boytac está documentada a partir de abril de 1514.

O risco inicial é de Boytaca (1501-02), que lançou os fundamentos da igreja e do claustro, cuja campanha de obra incluiu os arranques do portal principal, actualmente abrindo para um nártex abobadado formado pelo varandim coberto que estabelece ligação com as arcadas do corpo fronteiro, onde está sediado o Museu Nacional de Arqueologia.

A meio da fachada Sul, voltada para o Tejo, rasga-se o pórtico de João de Castilho, estruturado ao modo monumental, relicário de ourivesaria, sobrepujado pela estátua da Virgem de Belém e o Arcanjo S. Miguel, decorado com esculturas dos apóstolos, profetas, doutores da Igreja, sibilas e anjos.

A igreja é de planta longitudinal em cruz latina, com três naves cobertas por abóbada única, rebaixada, apoiada em oito pilares octogonais de grande altura, sistema que possibilita a criação de um espaço transparente, unificado e luminoso.

O claustro, a norte, é de dois andares abobadados, decorado com motivos relevados cristológicos pontuados por heráldica régia. A casa do capítulo, a nascente do claustro, foi reconstituída em 1884, e alberga o túmulo de Alexandre Herculano. O refeitório, é paralelo à parede Oeste do claustro e coberto por uma única abóbada abatida e polinervada.

O tipo de pagamento durante este período era feito à peça: na folha 78 da Ementa de Fevereiro de 1516 podemos ler algumas referências importantes, no que respeita às gárgulas: "Item pagou a Amtone pyz de hua garga q lavrou pêra a capelynha de sacrystya dozemtos rs. (...) It pagou a Mates Roiz (...) hua garga q lavrou, duzemtos rs (...) It pagou a d. ${ }^{\circ}$ molhado (...) hua garga q lavrou da sãcrestya, dozemtos rs" "(JOSE ALVES, 1991). Entre os oficiais portugueses esculpir gárgulas não devia ser um ofício especializado e exclusivo. Em abril de 
1516 D Manuel I redigiu o seu testamento, homenageando o mosteiro e elegendo-o para seu panteão. Em julho do mesmo ano, em consequência de uma Bula Papal, o mosteiro tornou-se cabeça da ordem hieronimita em Portugal e pretendia-se que evoluísse para um complexo monástico capaz de albergar uma centena de monges. O claustro de Santa Maria de Belém e a composição das suas gárgulas deve-se atribuir a Boytac e a João de Castilho pois parece-nos a hipótese mais plausível e a que tem colhido mais consenso entre a historiografia artística. No entanto as gárgulas claustrais não podem pertencer senão à coordenação de Castilho, pois são lavradas e colocadas em fase de acabamentos. O sistema hidráulico superior é composto por:

I. No corpo do complexo monástico que corresponde ao actual Museu da Marinha e Museu Nacional de Arqueologia, as águas pluviais caiem nos telhados e são enviadas para as gárgulas que as descarregam para o exterior do edifício.

II. No corpo da igreja virado para o portal secundário as águas são enviadas dos telhados directamente para as gárgulas e daí para um segundo telhado (que corresponde ás capelas adossadas à igreja), que as encaminham para outro registo de gárgulas e finalmente para o exterior do edifício.

III. No lado Noroeste do monumento (correspondente à actual Casa Pia de Lisboa) podemos verificar que as águas fazem o mesmo percurso que na solução anterior sendo que após serem enviadas para o segundo telhado, são de novo encaminhadas para um terraço e daí direcionadas para umas goteiras, de onde vão para o exterior do edifício.

IV. No "terreiro" que serve de passagem actual entre a igreja e a Biblioteca da Marinha podemos verificar que as águas são enviadas de duas formas: por um lado pelo terraço e por outro pelos telhados indo depois para as gárgulas e daí para o exterior.

V. No claustro principal as águas são actualmente enviadas dos telhados para um primeiro registo de gárgulas, que as colocam no terraço (inclinado) indo seguidamente para um segundo registo de gárgulas e daí para o exterior.

É importante ter em conta que existem no mosteiro de Santa Maria de Belém um número relativo de gárgulas que somente tem a função decorativa.

Nalguns casos é possível verificar que a função hidráulica foi suprimida na sequência de campanhas de restauro, levadas a cabo durante o século XIX.

Quanto aos telhados estes são inclinados a duas e quatro águas, assim sendo as águas ou são 
enviadas para o exterior do complexo monástico ou para o interior do claustro.

Tal como em outros edifícios que estudámos também este é composto por canais nos telhados e terraços que direcionam e distribuem as águas vindas dos telhados e terraços para a boca das gárgulas. Existem sessenta gárgulas no claustro de Santa Maria de Belém, quarenta no primeiro registo (piso inferior) e vinte no segundo (piso superior). No que respeita ao primeiro registo metade são somente decorativas ${ }^{7}$, visto não estarem rasgadas no topo e para além disso encontram-se tapadas, o que vem dificultar o escoamento das águas pluviais do primeiro para o segundo nível. Podemos visualizar a colocação recente de tubagens o que é um indicativo da tentativa de melhorar a drenagem das águas de um terraço ou telhado para o outro.

No que respeita ao programa iconográfico do claustro de Santa Maria de Belém, ele tem apaixonado os historiadores pela sua complexidade visual e sobrecarga simbólica. Nele se articulam a heráldica real, a iconografia cristã e muitos outros elementos decorativos embora exiba também uma quantidade significativa de símbolos alquímicos e herméticos, segundo hipóteses levantadas em investigações de A. Telmo ${ }^{8}$ (A. TELMO, 1997) e P. Pereira ${ }^{9}$ (PAULO PEREIRA, 2004). As gárgulas que compõem o claustro desempenharam importantes funções, quer em termos simbólicos, quer pedagógicos.

No que respeita ás intervenções de restauro que o mosteiro sofreu no séc. XIX, foram realizadas algumas gárgulas com qualidade muito inferior, identificando-se quase imediatamente. Após a investigação levada a cabo por Catarina Ferreira Barradas ${ }^{10}$ (CATARINA BARREIRA, 2010), podemos sistematizar a colocação das gárgulas no reinado de D. Manuel e D. João III, da seguinte forma:

\begin{tabular}{|l|l|l|l|}
\hline Campanhas & Reinados & Localização & Gárgulas \\
\hline $1^{\mathrm{a}}$ & D. Manuel & $\begin{array}{l}\text { Braço Norte do } \\
\text { Transepto }\end{array}$ & - Hibrido/Dragão \\
& & Cabeceira & - Porca \\
\cline { 2 - 5 } & & $\begin{array}{l}\text { Braço Sul do } \\
\text { Transepto }\end{array}$ & - Animal \\
\cline { 2 - 4 } & & & - Híbridos \\
& & & - Mulher \\
\hline
\end{tabular}




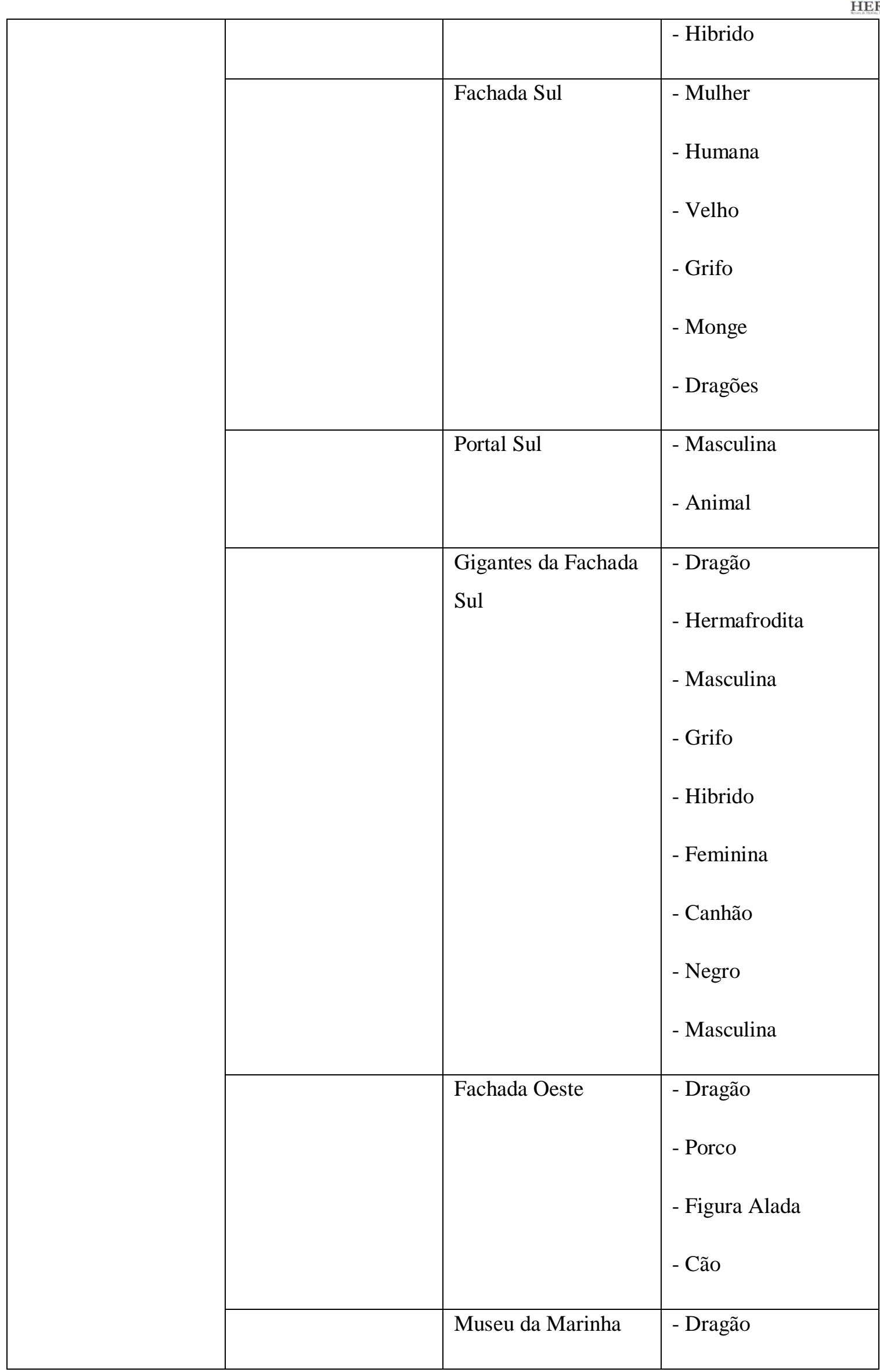




\begin{tabular}{|c|c|c|c|}
\hline & & & $\begin{array}{l}\text { - Harpia } \\
\text { - Cães }\end{array}$ \\
\hline & & $\begin{array}{l}\text { Fachada Lateral } \\
\text { Norte }\end{array}$ & $\begin{array}{l}\text { - Humanas } \\
\text { - Híbridos }\end{array}$ \\
\hline $2^{\mathrm{a}}$ & 1517 & Claustro piso térreo & $\begin{array}{l}\text { - Dragão } \\
\text { - Águia } \\
\text {-Dragões } \\
\text { antropomorfizados }\end{array}$ \\
\hline & & Claustro piso superior & $\begin{array}{l}\text { - Pássaro } \\
\text { - Dragão } \\
\text { - Galo } \\
\text { - Morcego } \\
\text { - Coruja } \\
\text {-Dragão Gastrocéfalo } \\
\text { - Grifo } \\
\text { - Masculina } \\
\text { - Macaco }\end{array}$ \\
\hline $3^{\mathrm{a}}$ & $\begin{array}{l}\text { D. João III } \\
\text { (1521 a 1557) }\end{array}$ & Claustro piso superior & - Masculina \\
\hline
\end{tabular}

Gráfico n. ${ }^{\circ} 2$ - Colocação de gárgulas 
3. Igreja de Nossa Senhora da Conceição: descrição histórica, artística, conservação e restauro e subsistema hidráulico superior

A igreja de Nossa Senhora da Conceição a Velha, situa-se bem no coração da cidade de Lisboa, na Rua da Alfandega, bem próxima da Praça do Comércio. O edifício actual deriva da antiga igreja da Conceição dos Freires, anterior templo destruído no grande terramoto de 1755 que assolou grande parte da cidade de Lisboa. Este templo anterior tinha origens na antiga sinagoga que foi cristianizada aquando da extinção da judiaria em 1496.

Este edifício do século XIII recebeu então muitos elementos do período manuelino, como é visível na fachada profusamente decorada ao estilo barroco, contudo albergando um largo número de elementos decorativos típicos do século XVI.

No portal manuelino está representada Nossa Senhora da Misericórdia, parte integrante da anterior igreja da Misericórdia, também destruída pelo terramoto. No portal estão esculpidos a imagem de Nossa Senhora da Misericórdia, figurando também o rei D. Manuel I, a rainha D. Leonor e o papa Leão X. Neste edifício existe uma única solução hidráulica onde a água cai no telhado de duas águas, vai para os canais seguindo para duas gárgulas e daí para o exterior.

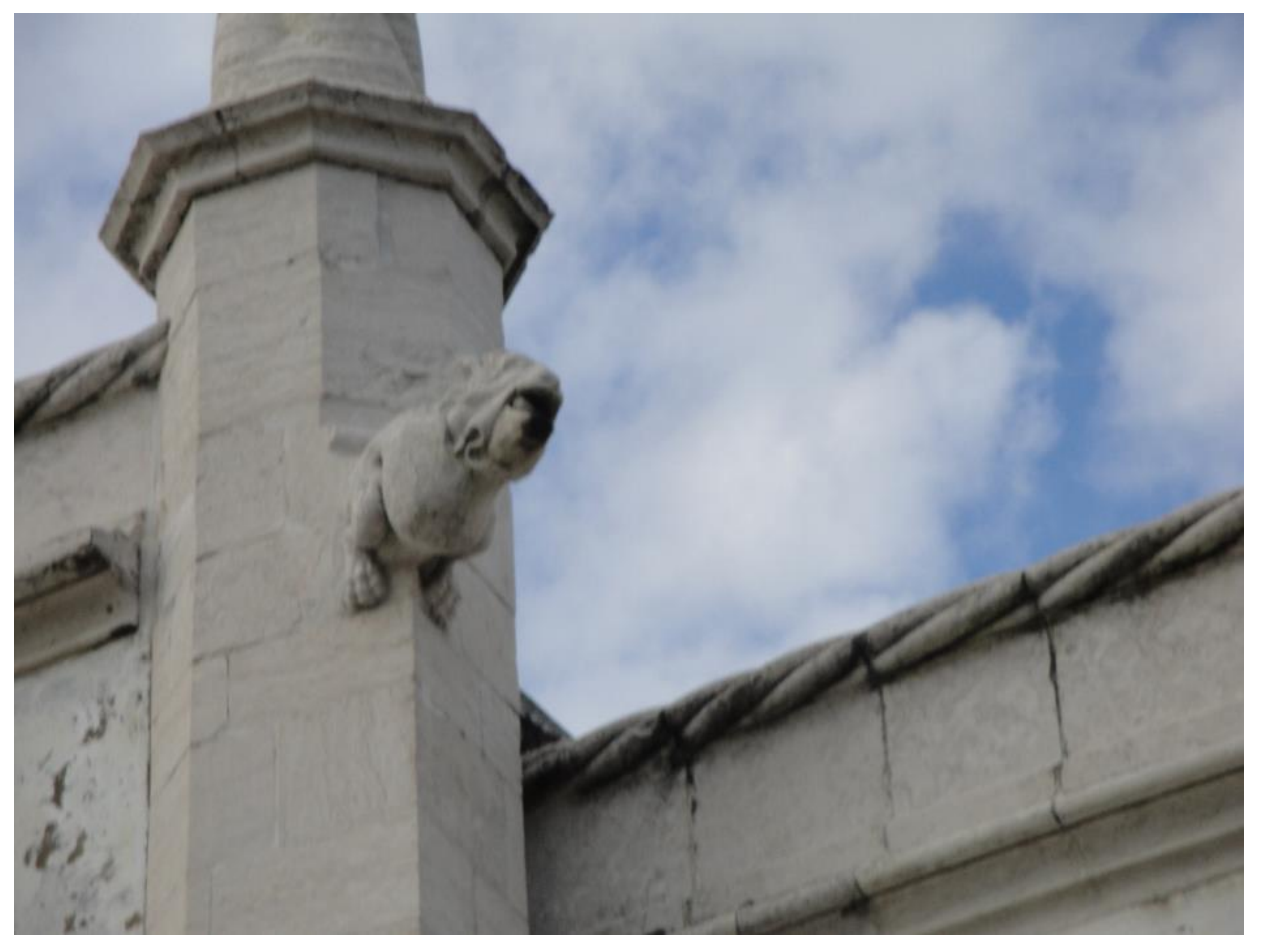

I. Ermida de S. Jerónimo: descrição histórica, artística, conservação e restauro e subsistema hidráulico superior 
Edificada em 1514, dentro dos terrenos da cerca do mosteiro de Santa Maria de Belém, foi concebida por Boytaca e concluída por Rodrigo Afonso. De planta quadrada, o corpo da capela é rematado superiormente por um grosso cordão e pináculos torsos, com gárgulas nos cantos. Os cunhais estão reforçados por quatro gigantes com função estrutural, que apoiam a sustentação da cobertura, em abóbada polinervada e panos murários. A capela tem sido restaurada ao longo dos séculos, sendo o restauro mais recente o que foi feito a par das grandes obras levadas a cabo no final do século XIX no mosteiro de Santa Maria de Belém, como prova a inscrição gravada sobre a pequena porta lateral: "Restaurada em 1886". Tal como no edifício anterior este é composto por telhados de duas águas com a queda de água dos telhados para os canais que distribuem as águas para as gárgulas e daí para o exterior. Após a investigação levada a cabo por Catarina Ferreira Barradas (CATARINA BARREIRA, 2011), podemos sistematizar a colocação das gárgulas no reinado de D. Manuel da seguinte forma:

\begin{tabular}{|l|l|l|l|}
\hline Campanhas & Reinados & Localização & Gárgulas \\
\hline $1^{\text {a }}$ & D. Manuel & Fachada Principal & - Animal \\
& $(1495$ a 1521) & & - Leão \\
\hline & & Fachada Sul & - Animal \\
\hline & & Cabeceira & - Dragão \\
& & & - Serpente \\
\hline & & Fachada Norte & - Humana \\
\hline
\end{tabular}

Gráfico n. ${ }^{\circ} 3$ - Colocação de gárgulas 


\section{Conclusões}

Em modo conclusão podemos afirmar que no mosteiro de Santa Maria de Belém existem gárgulas não funcionais devido às campanhas de restauro efectuadas no edifício. O subsistema hidráulico superior presente no mosteiro de Santa Maria de Belém e na catedral de Lisboa é mais complexo devido às grandes dimensões dos edifícios. Tanto na ermida de S. Jerónimo como na igreja da Conceição a Velha, só existe uma única solução hidráulica, devido em parte às pequenas dimensões dos edifícios. Tanto no mosteiro de Santa Maria de Belém como na catedral de Lisboa, os contrafortes são parte integrante do sistema hidráulico superior. Em todos os edifícios existem gárgulas. 


\section{Notas de rodapé}

${ }^{1}$ Ao mencionarmos as gárgulas e as goteiras consideramos que ambos os elementos possuem uma mesma função hidráulica. Estamos, contudo, cientes da função simbólica e iconográfica que as gárgulas possuem, e que é inexistente nas goteiras.

${ }^{2}$ ALMEIDA, Carlos Alberto Ferreira de, Barroca, Mário Jorge, História da Arte em Portugal - O Gótico, Lisboa, Editorial Presença, 2002, p. 58

${ }^{3}$ NETO, (Dir. Cient.) Maria João, Thomas Pitt. Observações de uma viagem a Portugal e Espanha (1760), S.1., IPPAR, 2006, p. 114

${ }^{4}$ ROSAS, Lúcia Maria Cardoso, Monumentos Pátrios. A Arquitectura religiosa medieval - Património e restauro (1835-1985), Vols. I e II, Faculdade de Letras da Universidade do Porto, 1995.

5 ALVES, José da Felicidade, O Mosteiro dos Jerónimos II - Das origens à actualidade, Lisboa, Livros Horizonte, 1991, p. 59

${ }^{6}$ ALVES, José da Felicidade, O Mosteiro dos Jerónimos II - Das origens à actualidade, Lisboa, Livros Horizonte, 1991, pp. 102-103

${ }^{7}$ Neste caso aplicamos o termo gárgula e não quimera pois defendemos que estas peças eram inicialmente funcionais acabando por se tornar unicamente decorativas após as campanhas de restauro levadas a cabo nos últimos séculos.

${ }^{8}$ TELMO, António, Horóscopo de Portugal, Lisboa, Guimarães Editores, 1997

${ }^{9}$ PEREIRA, Paulo, Enigmas - Lugares mágicos de Portugal. Idades do Ouro, Lisboa, Círculo de Leitores, 2004

${ }^{10}$ BARREIRA, Catarina Alexandra Martins Fernandes, Gárgulas: representações do feio e do grotesco no contexto português. Séculos XII e XVI, Vols. I e II, Lisboa, Faculdade de Belas Artes da Universidade de Lisboa, 2010

${ }^{11}$ BARREIRA, Catarina Alexandra Martins Fernandes, Gárgulas: representações do feio e do grotesco no contexto português. Séculos XII e XVI, Vols. I e II, Lisboa, Faculdade de Belas Artes da Universidade de Lisboa, 2010 


\section{Referências bibliográficas}

Almeida, Carlos Alberto Ferreira de, Barroca, Mário Jorge. 2002. História da Arte em Portugal - O Gótico. Lisboa: Editorial Presença.

Alves, José da Felicidade. 1991. O Mosteiro dos Jerónimos II - Das origens à actualidade. Lisboa: Livros Horizonte.

Barreira, Catarina Fernandes. As Gárgulas falam no claustro de Santa Maria de Belém, in, Sessão II Ciclos \& Trânsitos - Conventos e Mosteiros de Lisboa Associação Portuguesa de Historiadores da Arte.

Barreira, Catarina Alexandra Martins Fernandes. 2010. Gárgulas: representações do feio e do grotesco no contexto português. Séculos XII e XVI. Lisboa: Faculdade de Belas Artes da Universidade de Lisboa.

Fulcanelli. 2005. O mistério das catedrais. Lisboa: Edições 70.

Neto, (Dir. Cient.) Maria João. 2006. Thomas Pitt. Observações de uma viagem a Portugal e Espanha (1760). S.1.: IPPAR.

Pereiro, Paulo. 2004. Enigmas - Lugares mágicos de Portugal. Idades do Ouro. Lisboa: Círculo de Leitores.

Rosas, Lúcia Maria Cardoso. 1995. Monumentos Pátrios. A Arquitectura religiosa medieval Património e restauro (1835-1985). Porto: Faculdade de Letras da Universidade do Porto.

Telmo, António. 1997. Horóscopo de Portugal. Lisboa: Guimarães Edit 